\title{
Surface characteristics of the entomopathogenic fungus Beauveria (Cordyceps) bassiana
}

\begin{abstract}
Correspondence
Nemat O. Keyhani

keyhani@ufl.edu
\end{abstract}

Received 28 March 2007

Revised 5 July 2007

Accepted 10 July 2007

\author{
Diane J. Holder, Brett H. Kirkland, Michael W. Lewis \\ and Nemat O. Keyhani
}

Department of Microbiology and Cell Science, University of Florida, Gainesville, FL 32611, USA

\begin{abstract}
Marked differences in surface characteristics were observed among three types of single-cell propagules produced by the entomopathogenic fungus Beauveria bassiana. Atomic force microscopy (AFM) revealed the presence of bundles or fascicles in aerial conidia absent from in vitro blastospores and submerged conidia. Contact angle measurements using polar and apolar test liquids placed on cell layers were used to calculate surface tension values and the free energies of interaction of the cell types with surfaces. These analyses indicated that the cell surfaces of aerial conidia were hydrophobic, whereas those of blastospores and submerged conidia were hydrophilic. Zeta potential determinations of the electrostatic charge distribution across the surface of the cells varied from +22 to $-30 \mathrm{mV}$ for 16 -day aerial conidia at $\mathrm{pH}$ values ranging from 3 to 9 , while the net surface charge ranged from +10 to $-13 \mathrm{mV}$ for submerged conidia, with much less variation observed for blastospores, +4 to $-4 \mathrm{mV}$, over the same $\mathrm{pH}$ range. Measurements of hydrophobicity using microbial adhesion to hydrocarbons (MATH) indicated that the surfaces of aerial conidia were hydrophobic, and those of blastospores hydrophilic, whereas submerged conidia displayed cell surface characteristics on the borderline between hydrophobic and hydrophilic. Insect pathology assays using tobacco budworm (Heliothis virescens) larvae revealed some variation in virulence among aerial conidia, in vitro blastospores and submerged conidia, using both topical application and haemocoel injection of the fungal cells.
\end{abstract}

\section{INTRODUCTION}

As an alternative to chemical pesticides, the entomopathogenic fungus Beauveria (Cordyceps) bassiana is currently under intensive study as a promising biocontrol agent for insects and other arthropod pests (Kirkland et al., 2004a; Leathers et al., 1993; McCoy, 1990). The range of target organisms spans the classes of the Arthropoda, and practical biocontrol applications have ranged from agricultural pests to human disease agent-carrying organisms such as mosquitoes, sand flies and ticks (Reithinger et al., 1997; Samish et al., 2004; Scholte et al., 2005). The B. bassiana lifestyle is unusual in that in addition to being a necrotrophic parasite of a broad range of arthropods, it is a facultative saprophyte and can exist as a plant endophyte (Bing \& Lewis, 1991, 1992). An opportunistic pathogen, B. bassiana does not require any specialized route of entry towards susceptible host targets, and an array of depolymerases (proteases, chitinases) and secondary metabolites participate in the infection process (Charnley \& St Leger, 1991; El-Sayed et al., 1993; Fuguet et al., 2004; Kirkland

Abbreviations: AFM, atomic force microscopy; HI, hydrophobicity index; $\mathrm{HIC}$, hydrophobic-interaction chromatography; MATH, microbial adhesion to hydrocarbons. et al., 2005). Different infectious B. bassiana propagules can be isolated and selected for host targeting (Alves et al., 2002; Kirkland et al., 2004b; Thomas et al., 1987; Viaud et al., 1998). Thus, in addition to mycelial and hyphal growth, $B$. bassiana produces a number of mono-nucleated singlecell types, including aerial conidia, blastospores and submerged conidia, which can be isolated from agar plates, rich-broth submerged cultures and nutrient-limited submerged cultures, respectively (Boucias et al., 1988; Holder \& Keyhani, 2005). These cells display distinct morphological, biochemical and pathological characteristics, and attempts are being made to exploit these properties in pest targeting and/or the enhancement of virulence. Expressed sequence tag (EST) analysis of cDNA libraries derived from aerial conidia, blastospores and submerged conidia indicates robust and stage-specific gene-expression profiles among these cells (Cho et al., 2006).

The varied cuticles of target organisms represent the initial barrier to the pathogen, and attachment of infective fungal propagules is essential in establishing mycosis (Boucias \& Pendland, 1991; Fargues, 1984; Pendland et al., 1993). In this regard, the surface properties of the fungal cells form the basis for the host-pathogen interaction. The production and development of B. bassiana aerial conidia, 
in vitro blastospores and submerged conidia has been well defined (Bidochka et al., 1987; Hegedus et al., 1990; Thomas et al., 1987). These cells display different cell wall surface characteristics, as exemplified by differences in hydrophobicity and lectin-binding properties (Hegedus et al., 1992; Jeffs et al., 1999). A study of the attachment properties of the B. bassiana cell types revealed that aerial conidia adhere poorly to weakly polar surfaces, and rapidly to both hydrophobic and hydrophilic surfaces, although attachment to the latter surface type cannot be consolidated, and the cells can be rapidly washed off (Boucias et al., 1988; Holder \& Keyhani, 2005). In vitro blastospores, however, bind poorly to hydrophobic surfaces, moderately to weakly polar surfaces, and rapidly to hydrophilic surfaces. Submerged conidia display the broadest binding spectrum, and can attach to hydrophobic, weakly polar and hydrophilic surfaces. Additionally, a rodlet layer, presumably consisting of hydrophobin(s) proteins, was detected on the surfaces of aerial conidia, but not on those of either blastospores or submerged conidia under the conditions tested (Holder \& Keyhani, 2005).

This report describes the surface characteristics of $B$. bassiana aerial conidia, in vitro blastospores and submerged conidia in terms of the factors that contribute to mediating the adhesion process, including electrostatic charge and hydrophobicity. Each cell type displayed distinct surface features in terms of morphology and biophysical parameters, including surface charge and hydrophobicity. Insect pathology assays revealed that all three cell types were infectious, although some variation was noted. These data indicate that $B$. bassiana produces distinct infectious cell types which allow it to interact with a variety of substrata, and may help account for the broad invertebrate host range of the fungus.

\section{METHODS}

Cultivation of fungi. B. bassiana (ATCC 90517) was routinely grown on either Potato dextrose agar (PDA) or Sabouraud dextrose $+1 \%$ yeast extract agar plates (SDAY). Plates were incubated at $26{ }^{\circ} \mathrm{C}$ for 10-12 days and aerial conidia were harvested by flooding the plate with sterile deionized water $\left(\mathrm{dH}_{2} \mathrm{O}\right)$. Conidial suspensions were filtered through a single layer of Mira cloth and final spore concentrations were determined by direct counting using a haemocytometer. Blastospores were produced in Sabouraud dextrose $+1 \%$ yeast extract liquid broth cultures (SDY) using conidia harvested

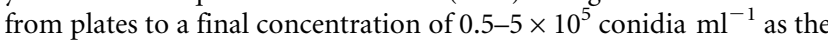
inoculum. Cultures were grown for $3-4$ days at $26{ }^{\circ} \mathrm{C}$ with aeration. Cultures were filtered (twice) through glass wool to remove mycelia, and the concentration of blastospores was determined by direct counting. Submerged conidia were produced in TKI broth using fructose as the carbon source, as described by Cho et al. (2006). For all cell types, Mira cloth- or glass wool-filtered cell suspensions were harvested by centrifugation $\left(10000 \mathrm{~g}, 15 \mathrm{~min}, 4{ }^{\circ} \mathrm{C}\right)$, washed two times with sterile $\mathrm{dH}_{2} \mathrm{O}$, and resuspended to the desired concentration (typically $10^{7}-10^{8}$ cells $\mathrm{ml}^{-1}$ ).

Atomic force microscopy (AFM). Atomic force micrographs were made using a Digital Instruments Multimode SPM atomic force microscope (model MMAFM-2) placed on a marble stone platform.
Images were taken in either tapping or contact mode using a $\mathrm{Si}_{3} \mathrm{~N}_{4}$ probe (Digital Instruments, model NP-20, spring constant $=$ $0.12 \mathrm{~N} \mathrm{~m}^{-1}$ ). Fungal cells were placed on $1.2 \mu \mathrm{m}$ pore-size Millipore filters and air-dried for 1-4 h before examination. Images were collected at 512 lines per scan with a scan rate of $0.96 \mathrm{~Hz}$ and tip velocity of $30.6 \mu \mathrm{m} \mathrm{s}^{-1}$. Data from the micrographs were analysed using Nanoscope SPM v4.42 and SPM Image Magic demo v1.10.

\section{Determination of cell surface hydrophobicity}

Microbial adhesion to hydrocarbons (MATH) assay. Cell surface hydrophobicity was determined essentially as described by Smith et al. (1998). Briefly, aerial conidia, blastospores and submerged conidia were washed into PUM buffer (per litre: $22.2 \mathrm{~g} \mathrm{~K}_{2} \mathrm{HPO}_{4}, 7.26 \mathrm{~g}$ $\mathrm{KH}_{2} \mathrm{PO}_{4}, 1.8 \mathrm{~g}$ urea, $0.2 \mathrm{~g} \mathrm{MgSO}_{4} \cdot 7 \mathrm{H}_{2} \mathrm{O}$, final $\mathrm{pH} 7.1$ ). Fungal cell suspensions were adjusted to $\mathrm{OD}_{470} 0.4$ and dispensed $(3 \mathrm{ml})$ into acid-washed glass tubes $(12 \times 75 \mathrm{~mm})$. Hexadecane $(300 \mu \mathrm{l})$ was then added to each tube and the tubes were vortexed three times for $30 \mathrm{~s}$. The vortexed tubes were allowed to stand at room temperature for $15 \mathrm{~min}$ before the hexadecane phase was carefully removed and discarded. Tubes were then cooled to $5{ }^{\circ} \mathrm{C}$ and any residual solidified hexadecane removed. The tubes were then returned to room temperature and the $A_{470}$ of the resultant cell suspensions was determined. The hydrophobic index was calculated using the following equation: $\left(A_{470}\right.$, control $\left.-A_{470 \text {, hexadecane treated }}\right) /\left(A_{470, \text { control }}\right)$.

Hydrophobic-interaction chromatography (HIC) assay. Fungal cells

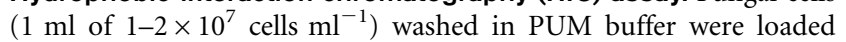
onto $1 \mathrm{ml}$ columns containing either phenyl-Sepharose or unmodified (CL4B) Sepharose (Sigma) pre-equilibrated in PUM buffer. Columns were subsequently washed with PUM buffer $(4 \mathrm{ml})$ and the number of fungal cells recovered in the eluate was determined using a haemocytometer. The hydrophobicity index (HI) was calculated using the following equation: [(percentage cells eluted from unmodified Sepharose)-(percentage cells eluted from phenylSepharose)]/(percentage cells eluted from unmodified Sepharose).

Contact angle determination. Contact angle measurements of the B. bassiana cell types were determined using a Ramehart model 500 Advanced goniometer with automated drop dispenser and tilting plate, and DropImage Advanced software. Advancing angle measurements were determined just prior to movement of the water drop. Briefly, a $10 \mu \mathrm{l}$ drop of solution was placed onto the surface of the substrata to be tested. The stage and the camera were tilted at $10^{\circ}$ increments until the drop was on the verge of movement. The leading edge (dynamic) contact angle was then determined. Experiments were performed with sterile $\mathrm{dH}_{2} \mathrm{O}, 2$-bromonaphthalene and glycerol at room temperature and 50-55\% relative humidity. Each experiment was performed using at least 10 drops on triplicate samples, using three different batches of each cell type.

Insect bioassays. Second- to fourth-instar Heliothis virescens (Fabricius) (tobacco budworm) were used in bioassays testing the virulence of the $B$. bassiana cell types. Aerial conidia, in vitro blastospores and submerged conidia were isolated as described above. Aerial conidia were harvested from agar plates directly in sterile $\mathrm{dH}_{2} \mathrm{O}$, whereas in vitro blastospores and submerged conidia were washed twice in sterile $\mathrm{dH}_{2} \mathrm{O}$ before use. Two different assay conditions were tested for each cell type. (1) Topical application: the larvae were dipped in a solution of $10^{8}$ fungal spores $\mathrm{ml}^{-1}$, and the excess liquid on the insect body was removed with dry paper towel; control larvae were treated with sterile $\mathrm{dH}_{2} \mathrm{O}$. (2) Intrahemocoel injection: the larvae were injected with $5 \mu \mathrm{l}$ of $10^{8}$ fungal spores $\mathrm{ml}^{-1}$ into the haemocoel cavity; controls were injected with $5 \mu$ sterile $\mathrm{dH}_{2} \mathrm{O}$. Experimental and control larvae were placed in individual plastic chambers containing modified wheatgerm-based 
insect media (Greene et al., 1976) and incubated at $24{ }^{\circ} \mathrm{C}$. The number of dead insects was recorded daily. For each experimental condition, 20-40 larvae were used, and all experiments were repeated three times.

\section{RESULTS}

\section{AFM}

Detailed surface topological features of live B. bassiana cells could be distinguished by AFM (Fig. 1). AFM allows the visualization of live cells without fixation, and was used to provide resolution at the micrometre level of surface features of freshly harvested cells. Fascicle bundles, presumably composed of assembled hydrophobin(s) protein rodlets, were clearly visible on $B$. bassiana aerial conidia (Fig. 1a, d), and could be removed by sonication
(Boucias et al., 1988). Rodlet filaments could faintly be distinguished within the fascicles (Fig. 1g). In contrast, no bundles or fascicles were visible on either blastospores or submerged conidia. The blastospore surface appeared smooth (Fig. 1b, e), whereas the submerged conidial surface was rough, and a circular ring was apparent on some of the latter cells (Fig. 1c, f). In several instances, bipolar germination was noted for B. bassiana (Fig. 1h), and this has been reported to correlate with its infectious nature (Talaei-Hassanloui et al., 2006). No fascicles were visible on the germ tubes or hyphae of germinating aerial conidia, although fascicles appeared to remain on the conidium during germination (Fig. 1i, j). AFM images of the germinated conidium revealed fascicles throughout the mother cell, and the lack of fascicles on the slopes of the images presented is due to cantilever artefacts at the resolution employed.
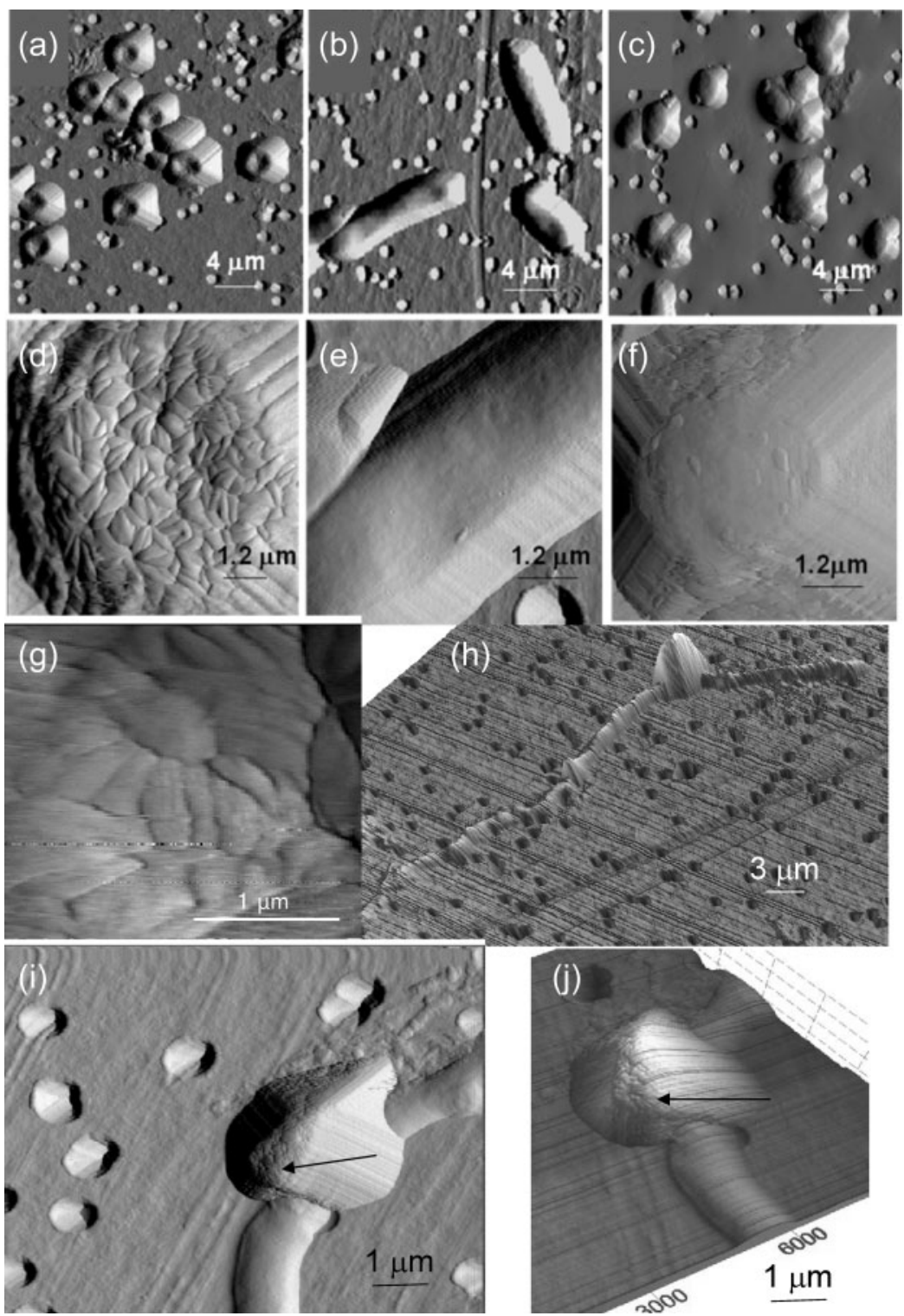

Fig. 1. Atomic force micrographs of $B$. bassiana spore types and germinating conidia. (a, d, g) Aerial conidia: note surface fascicles presumably composed of hydrophobin rodlets [rodlet filaments faintly visible in $(\mathrm{g})$ ]; $(\mathrm{b}, \mathrm{e})$ in vitro blastospores; (c, f) submerged conidia; (h) bipolar germination of aerial conidia. ( $i, j$ ) Higher resolution of germinating aerial conidia: note the fascicles still present on the germinated conidia (arrows). 


\section{Contact angle measurement}

Microbial lawns were generated by depositing fungal cells onto glass coverslips. In the case of aerial conidia the glass was treated with Sigmacote to siliconize the surface, allowing efficient attachment of the cells. Microscopic visualization of deposited cells was used to gauge the homogeneity of the microbial lawn. Cell densities ranged from $1 \times 10^{6}$ to $5 \times 10^{6}$ fungal cells $\mathrm{mm}^{-2}$, equivalent to microbial lawns $50-100$ cells thick. Samples were dried in covered Petri dishes for 2-4 h before use. Contact angle measurements were taken for each of the B. bassiana cell types using water, $\alpha$-bromonaphthalene and glycerol droplets (Fig. 2, Tables 1 and 2). These determinations revealed critical differences in cell wall physicochemical surface properties, including surface tension, charge and hydrophobicity, among aerial conidia, blastospores and submerged conidia. Aerial conidia displayed greater affinity for the apolar liquid (lower contact angle with $\alpha$ bromonaphthalene) than for either water or glycerol. Intriguingly, although both blastospores and submerged conidia displayed overall greater affinity for water than for the apolar solvent, the relative affinity of the latter two cell types for the apolar solvent was lower than that of aerial conidia. Overall analysis (of the three tested liquids) revealed that the apolar component $\left(\gamma_{s}^{\mathrm{LW}}\right)$ of aerial conidia was much greater than that of submerged conidia and blastospores, indicating that the surfaces of aerial conidia are more apolar than those of the other two cell types.

The hydrophobicity of the $B$. bassiana cell types was calculated using the surface tension values (Leckband \& Israelachvili, 2001; Strevett \& Chen, 2003) and evaluated as the interfacial free energy of interaction $\left(\Delta G_{\mathrm{iwi}}^{\mathrm{IF}}\right)$. This value represents the degree to which the attraction of the cells to water is greater or smaller than the attraction of water molecules to each other. When the value for this free energy of interaction of the solid molecule in water is repulsive $\left(\Delta G_{\text {iwi }}>0\right)$, the molecule is considered hydrophilic and will tend to disperse in water. In contrast, the more negative the $\Delta G_{\text {iwi }}$, the greater the hydrophobicity of the entity, and the greater the likelihood that the particles will aggregate in aqueous solution. According to this analysis, aerial conidia were the most hydrophobic, and are likely to aggregate in water, consistent with observations of the behaviour of these cells in aqueous solution, as low concentrations of detergent are often added to decrease conidial aggregation. In contrast, blastospores and submerged conidia were hydrophilic, with the latter somewhat less hydrophilic than the former.

\section{Zeta potential}

The surface charges of the three cell types were evaluated by means of zeta potential values (Strevett \& Chen, 2003; Wilson et al., 2001). Mean zeta potential values for aerial conidia, blastospores and submerged conidia were obtained over a $\mathrm{pH}$ range from 3 to 10 (Fig. 3). Since the surface charge of aerial conidia of other fungi are known to differ depending upon the age of the spores, both 16-day- and 20day-old aerial conidia were examined. The results revealed that 16-day aerial conidia displayed the highest positive zeta potential $(+22 \pm 2 \mathrm{mV})$ at low $\mathrm{pH}$ (3), which rapidly became negative by $\mathrm{pH} 5$, reaching a net negative surface charge of $-30 \pm 4 \mathrm{mV}$ at $\mathrm{pH} 8-9$. In order to obtain the zero potential, i.e. the $\mathrm{pH}$ at which the net surface charge of the cells is zero, the data were fitted using polynomial equations. For 16-day aerial conidia, regression analysis yielded the equation, $y=-0.09 x^{3}+2.3 x^{2}-25.3 x+80.6$, $r^{2}=0.999$, resulting in a zero potential of 4.9. Older conidia (20 days) displayed a more negative shift across the $\mathrm{pH}$ spectrum starting at $+10 \pm 2 \mathrm{mV}$ at $\mathrm{pH} 3.0$ and decreasing to $-50 \pm 2 \mathrm{mV}$ at $\mathrm{pH} 9.0$. The data were fitted to the equation $y=-0.2 x^{3}+3.4 x^{2}-24.2 x+55, r^{2}=0.9986$, yielding a zero potential of 3.9. Submerged conidia also displayed a net positive zeta potential $(+10 \pm 2 \mathrm{mV})$ at low $\mathrm{pH}$ that decreased to $-13 \pm 2 \mathrm{mV}$ at $\mathrm{pH} 9$, whereas blastospores displayed the smallest $\mathrm{pH}$-dependent surface-charge variation, from a small net positive charge $(+4 \pm 1 \mathrm{mV})$ at $\mathrm{pH} 3.0$ to a small net negative charge $(-4 \pm 1 \mathrm{mV})$ at $\mathrm{pH} 9$. Regression analyses for the latter two datasets yielded the equations $y=-0.17 x^{3}+3.3 x^{2}-23 x+51.1, r^{2}=0.9963$, and $y=-0.11 x^{3}+2.1 x^{2}-13.7 x+28.7, \quad r^{2}=0.9543, \quad$ with zero potentials calculated to be 4.1 and 4.2 for submerged conidia and blastospores, respectively. At a physiological $\mathrm{pH}$ value of 7.0, 16- and 20-day-old aerial conidia displayed net surface charge values of -15 and $-22 \mathrm{mV}$, respectively. In contrast, the surface charges on submerged conidia and blastospores were much smaller, -8 and $-2 \mathrm{mV}$, respectively, at $\mathrm{pH}$ 7.0.

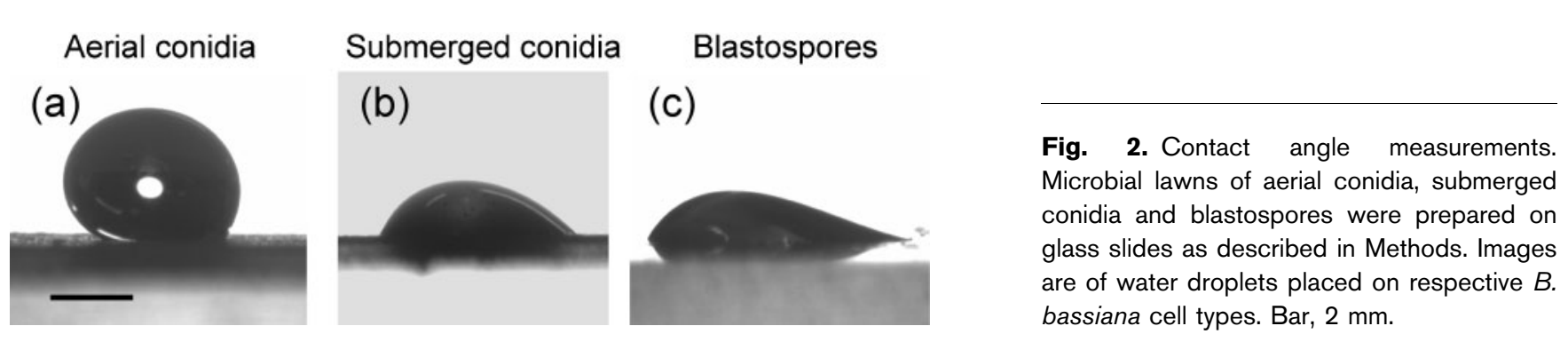


Table 1. Contact angle and calculated interfacial $\left(\Delta G_{\mathrm{iwi}}^{\mathrm{IF}}\right)$ and polar $\left(\Delta G_{\mathrm{iwi}}^{\mathrm{AB}}\right)$ free energy values for the $B$. bassiana cell types

\begin{tabular}{|c|c|c|c|c|c|}
\hline \multirow[t]{2}{*}{ B. bassiana cell type } & \multicolumn{3}{|c|}{ Contact angle } & \multicolumn{2}{|c|}{ Hydrophobicity } \\
\hline & $\mathrm{dH}_{2} \mathrm{O}$ & 1-Bromo-naphthalene & Glycerol & $\Delta G_{\mathrm{iwi}}^{\mathrm{AB}}$ & $\Delta G_{\mathrm{iwi}}^{\mathrm{IF}}$ \\
\hline Aerial conidia & $120.3 \pm 2.5^{\circ}$ & $66.2 \pm 0.5^{\circ}$ & $112.7 \pm 0.9^{\circ}$ & 47.2 & -34.8 \\
\hline Blastospores & $23.3 \pm 1.8^{\circ}$ & $33.6 \pm 0.4^{\circ}$ & $59.4 \pm 1.8^{\circ}$ & 187.4 & 74.4 \\
\hline Submerged conidia & $30.6 \pm 1.0^{\circ}$ & $56.4 \pm 0.8^{\circ}$ & $53.6 \pm 1.1^{\circ}$ & 167.1 & 46.0 \\
\hline
\end{tabular}

\section{Measurement of cell surface hydrophobicity}

Two methods were used to assess the cell surface hydrophobicity of the different $B$. bassiana cell types. In the first, a MATH assay in which cells partition between two immiscible solutions (water and hexadecane) was used (Fig. 4). In this assay, entities with $\mathrm{HI}>0.7$ are considered hydrophobic $(\mathrm{HI}=$ no. cells in organic phase/total no. cells). Aerial conidia were clearly hydrophobic and distributed into the organic phase $(\mathrm{HI}=0.88)$, whereas blastospores were hydrophilic, predominantly localizing to the aqueous phase $(\mathrm{HI}=0.4)$. Interestingly, submerged conidia partitioned to a slightly greater extent into the organic phase rather than the aqueous phase $(\mathrm{HI}=0.72)$, with cell surface characteristics apparently on the borderline between hydrophobic and hydrophilic. A second assay, involving HIC, in which the binding of cells to phenylSepharose and unmodified Sepharose is used as an indicator of the hydrophobic nature of particle surfaces, confirmed the results of the MATH assay (Fig. 4).

\section{Insect bioassays}

Second- to fourth-instar $H$. virescens (tobacco budworm) larvae were used to assess the infectivity of the $B$. bassiana cell types. Bioassays were performed by either topical application or haemocoel injection of the fungal cells. Topical application is the method used in biological control applications and reflects the natural route of infection, since B. bassiana does not require any specialized route of entry, and fungal cells will germinate, grow and eventually penetrate the insect cuticle essentially anywhere on the surface of the host. Upon topical application, in vitro blastospores gave rise to a slightly earlier onset of disease and mortality than either submerged conidia or aerial conidia (Fig. 5a). Onset of disease after application of aerial conidia took $\sim 3-4$ days, eventually resulting in similar levels of mortality by day 8 as those seen with blastospores and submerged conidia. The early onset of mortality seen using blastospores is likely due to the faster growth rate observed with these cells as compared to submerged conidia and aerial conidia. In the case of aerial conidia, germination can take between 16 and $24 \mathrm{~h}$, whereas blastospores and submerged conidia can produce additional cells (depending upon the availability of nutrients) within a few hours.

During the infectious cycle, fungal germ tubes eventually penetrate into the host haemocoel. In the haemocoel, the fungus produces distinct single cells termed in vivo blastospores (dissimilar to the in vitro blastospores) that are able to evade the host immune system. In order to test whether the three in vitro $B$. bassiana cell types were competent in differentiating into in vivo blastospores and evading the host immune system, fungal cells were injected directly into the haemocoel of $H$. virescens (Fig. 5b). These data revealed that in vitro blastospores were the most robust, resulting in approximately $75 \%$ mortality 2 days post-injection. Submerged conidia were slightly less virulent, resulting in $\sim 40 \%$ mortality 2 days post-infection, although by days $7-8$, the overall mortality was similar between the two cell types. Aerial conidia were noticeably less virulent, resulting in only $10 \%$ mortality 2 days postinfection, reaching $\sim 55 \%$ by day 10 . A large variation using aerial conidia was noted, however, which could be due to variation in the cultivation conditions (i.e. cell production and harvesting from agar plates), and which does not occur when cells are harvested from liquid

Table 2. Calculated surface energy values

All units are $\mathrm{mJ} \mathrm{m}^{-2}$.

\begin{tabular}{|c|c|c|c|c|c|}
\hline \multirow[t]{3}{*}{ B. bassiana cell type } & \multicolumn{5}{|c|}{ Surface energy } \\
\hline & \multirow[t]{2}{*}{ Polar, $\gamma^{\mathrm{AB}}$} & \multirow[t]{2}{*}{ Apolar, $\gamma_{\mathrm{s}}^{\mathrm{LW}}$} & \multirow[t]{2}{*}{ Total, $\gamma_{s}^{\text {total }}$} & \multicolumn{2}{|c|}{ Polar components } \\
\hline & & & & Acid, $\gamma^{+}$ & Base, $\gamma^{-}$ \\
\hline Aerial conidia & $9.7 \pm 1.5$ & $33.3 \pm 0.6$ & $43.0 \pm 1.1$ & $4.3 \pm 0.4$ & $5.5 \pm 1.5$ \\
\hline Blastospores & $10.8 \pm 2.3$ & $23.6 \pm 0.3$ & $34.4 \pm 1.3$ & $0.4 \pm 0.2$ & $86.1 \pm 3.7$ \\
\hline Submerged conidia & $23.3 \pm 1.1$ & $16.3 \pm 0.4$ & $39.6 \pm 0.8$ & $2.0 \pm 0.3$ & $68.4 \pm 2.0$ \\
\hline
\end{tabular}



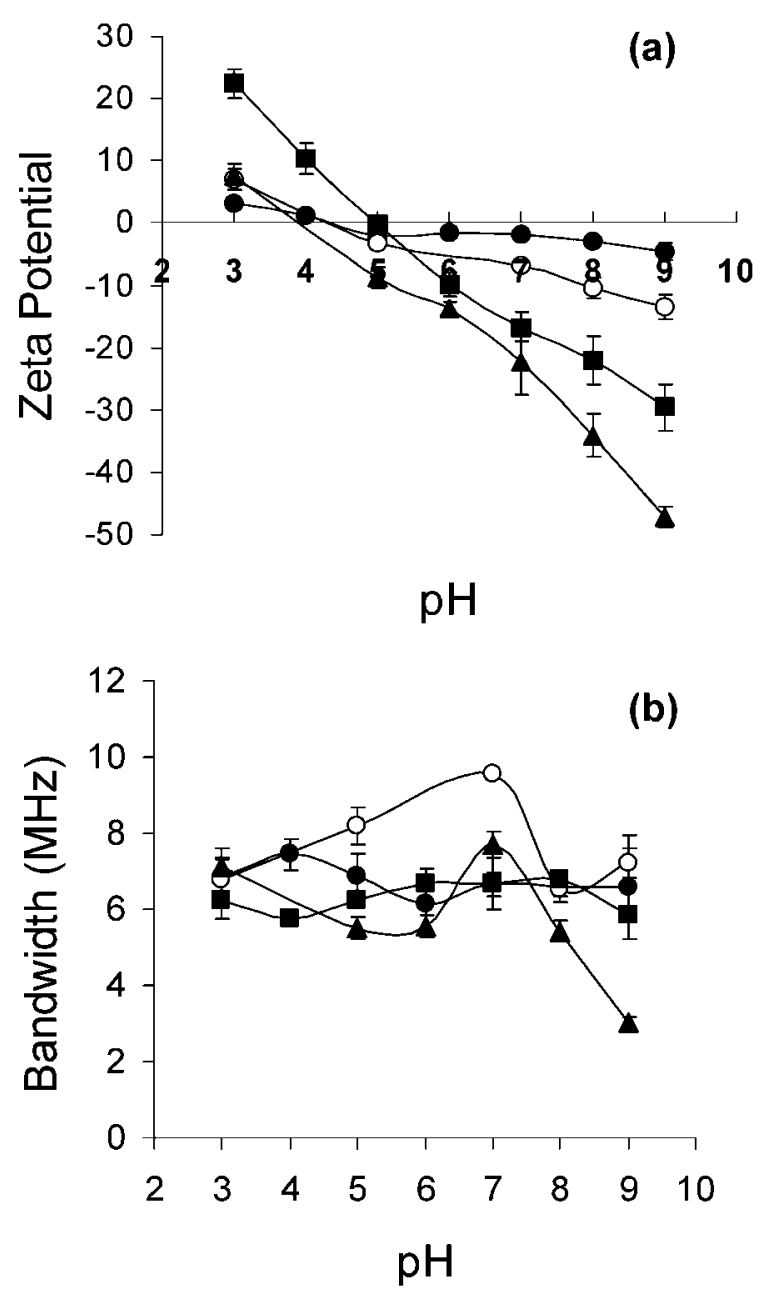

Fig. 3. Zeta potential (a) and spectrum width (b) of $B$. bassiana aerial conidia ( $\boldsymbol{\square}, 16$ days; $\boldsymbol{\Lambda}, 20$ days). ( $(\bullet)$ Blastospores; $(\bigcirc)$ submerged conidia.

cultures (i.e. in vitro blastospore and submerged conidia cultivation).

\section{DISCUSSION}

Fungal cells display a wide range of surface physicochemical properties that allow them to interact and adhere to substrata. Cell surface hydrophobicity is associated with increased virulence of Candida strains, and the hydrophobic rodlet layer of Aspergillus conidia appears to confer protection against host immune reactions (Hazen, 2004; Paris et al., 2003; Singleton et al., 2005). In the latter case, the determination of surface biophysical features of Aspergillus spores has revealed a role for the rodlet layers and their hydrophobin constituents in contributing to hydrophobicity, adhesion and resistance to killing by alveolar macrophages of the fungal cells (Dynesen \& Nielsen, 2003; Girardin et al., 1999; Paris et al., 2003; Stringer \& Timberlake, 1995; Thau et al., 1994).

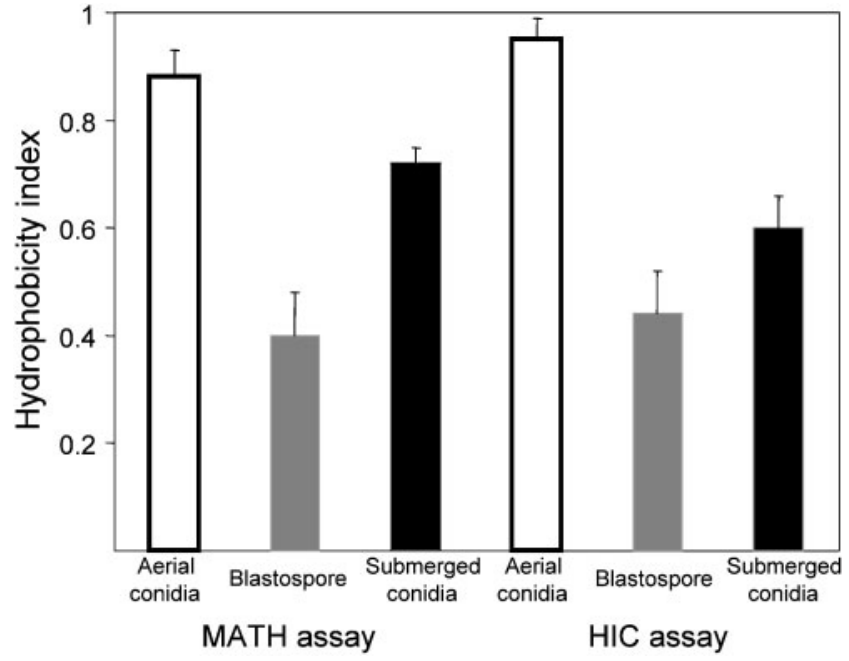

Fig. 4. Cell surface hydrophobicity of the three $B$. bassiana spore types assessed by MATH assay and HIC.

Entomopathogenic fungal spore surfaces range from hydrophobic, exemplified by fungi such as Nomuraea rileyi, Metarhizium anisopliae and Paecilomyces fumosoroseus, all of which possess defined outer rodlet layers, to hydrophilic, as seen in Hirsutella thompsonii and Verticillium lecanii, often characterized by the lack of a rodlet layer but containing an outer mucilaginous coat produced during spore maturation (Boucias \& Pendland, 1991). AFM has been used to visualize the surface features of live fungal cells (Dufrene, 2000; Zhao et al., 2005). Highresolution AFM micrographs of Aspergillus nidulans have revealed alterations to the spore rodlet layer during swelling in aqueous solutions, and ultrastructural features of newly deposited walls at hyphal tips as well as in mature walls (Ma et al., 2005, 2006). In the present study, AFM was used to examine gross morphological differences among the live spore types that were briefly air-dried before imaging. Initial experiments using an aqueous AFM cell chamber resulted in images that were not as clear as the ones presented, although future experiments imaging the cell types in an aqueous environment are warranted. $B$. bassiana aerial conidia contained fascicle bundles that were not present on either submerged conidia or blastospores. Surfaces of blastospores were smooth, whereas those of submerged conidia were more granulated in appearance. These results are consistent with the lack of SDS-insoluble, trifluoroacetic acid (TFA)-soluble proteins in the latter two cell types and their presence in aerial conidia (Holder \& Keyhani, 2005). Interestingly, from our results, no fascicles were visible on germ tubes emanating from aerial conidia, suggesting little membrane fluidity between spore and growing germ tube.

Hydrophobicity and zeta potential measurements have been used to predict the binding preferences of the fungal cells. Analysis of the cell surface properties of 

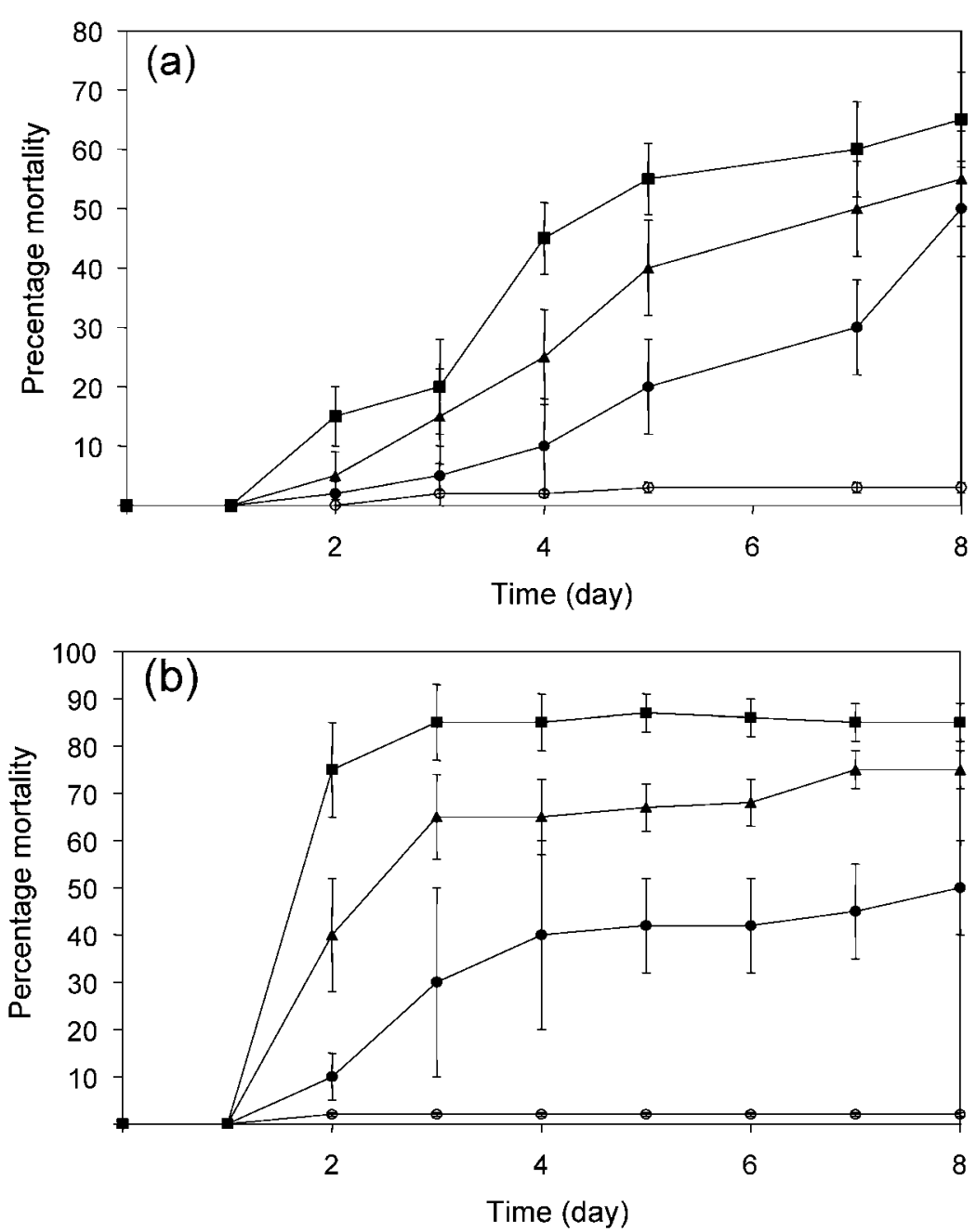

Fig. 5. Insect bioassays. $H$. virescens larvae were treated either topically (a) or via intrahaemocoel injection (b) with $B$. bassiana in vitro blastospores ( $\boldsymbol{\square})$, submerged conidia $(\boldsymbol{\Delta})$, aerial conidia $(\boldsymbol{O})$ or mock-treated controls $(\bigcirc)$, as described in Methods. The percentage mortality over the indicated timecourse is presented.
Cryptosporidium oocytes has revealed a preference for adhesion to glass rather than hydrophobic plastic materials, although cell surface hydrophobicity increases with increasing ionic strength of the medium (Drozd \& Schwartzbrod, 1996). In contrast, conidia of the mycoparasite Coniothyrium minitans are hydrophobic, although in this case, conidial hydrophobicity decreases with culture age for some isolates (Smith et al., 1998). Similarly, a comparison of two cell types of Trichoderma harzianum, a potential biological control agent of phytopathogenic fungi, reveals that aerial conidia display higher UV resistance and longer viability, and are more hydrophobic than submerged conidia, which are hydrophilic (Munoz et al., 1995). Contact angle measurements, microbial adhesion to solvents and zeta potential determinations of blastospores of the entomopathogenic fungus $P$. fumosoroseus indicate that these cells have a hydrophilic, basic monopolar surface, and are negatively charged under neutral conditions (Dunlap et al., 2005). Our results indicate that $B$. bassiana produces cells with divergent surface properties that are likely to confer distinct selective advantages in response to varying environmental conditions, although the nature of these advantages remains to be explored. Hydrophobicity was examined using three different methods: partitioning of cells in organic vs aqueous solvents (MATH), HIC and contact angle measurement. The first two methods gave almost identical HIs for the cells tested. Contact angle measurements using non-polar and polar probe liquids allowed the estimation of surface energy parameters. The polar component of aerial conidia $\left(\gamma^{\mathrm{AB}}\right)$ was equally distributed into the base $\left(\gamma^{-}\right)$and acid $\left(\gamma^{+}\right)$surface energy parameters, being 4.3 and $5.5 \mathrm{~mJ} \mathrm{~m}^{-2}$, respectively. Since monopolar surfaces with $\gamma^{-}>28 \mathrm{~mJ} \mathrm{~m}^{-2}$ are repulsive when dissolved or suspended in water (van Oss et al., 1987), these results suggest that aerial conidia will aggregate in aqueous solutions. In contrast, the large base $(86.1$ and $\left.68.4 \mathrm{~mJ} \mathrm{~m}^{-2}\right)$ as compared to acid $\left(0.4\right.$ and $\left.2.0 \mathrm{~mJ} \mathrm{~m}^{-2}\right)$ surface energy components of blastospores and submerged conidia, respectively, indicate that these cells would be repulsive when suspended in water.

Overall, aerial conidia are hydrophobic and represent the more resistant spore type, but are slower growing than 
blastospores and submerged conidia. Hydrophobic interactions predominate in the case of aerial conidia and are likely to be the most important force in the host-pathogen interaction. Although they are hydrophobic, the net negative surface charge of aerial conidia at neutral $\mathrm{pH}$ may help account for their ability to bind hydrophilic surfaces weakly (Holder \& Keyhani, 2005). A negative shift in the surface electrostatic charge distribution was noted for aerial conidia as they aged. This could be due to the production of increasing amounts of surface anionic species over time, or the unmasking of negative charges as the spores dry. Similar experiments could not be performed with blastospores and submerged conidia, as these cells are not stable and will either grow (i.e. germinate or microcycle conidiate) if sufficient nutrients are present or lose viability over a similar time-course.

Although further experimentation is needed, blastospores are fast growing and seem to be able to evade the host immune system better than the aerial conidia. In contrast to the aerial conidia, electrostatic charge appears to play a significant role in adhesion for the in vitro blastospores. The surface charge distribution of these cells is consistent with their ability to bind weakly polar and hydrophilic substrata (Holder \& Keyhani, 2005). Finally, submerged conidia display intermediate surface properties in terms of hydrophobicity and electrostatic charge. These cells can grow under nutrient-limiting conditions and are likely to exist on insect surfaces and during host-parasite competition for nutrients. The intermediate surface hydrophobicity values reported in this study again may help account for the adhesive nature of these cells, which were able to bind to hydrophobic, weakly polar and hydrophilic surfaces (Holder \& Keyhani, 2005).

The different $B$. bassiana cell types also express differential lectin-binding properties (Hegedus et al., 1992). All three cell types bound concanavalin A (Con A); however, whereas both aerial conidia and submerged conidia bound wheatgerm agglutinin (WGA), the Phaseolus vulgaris phytohaemagglutinin P (PHA-P) and the Ricinus communis agglutinin 1 (RCA) blastospores did not bind the first two substrates and interacted only weakly with the third. Furthermore, only aerial conidia showed a weak reaction against soybean agglutinin. Similar to our results with $H$. virescens, in topical applications all three cell types are pathogenic towards the migratory grasshopper Melanoplus sanguinipes, with the highest virulence reported for grasshoppers infected with blastospores (Hegedus et al., 1992). Direct haemocoel challenge of $H$. virescens with the different cell types did reveal that blastospores and submerged conidia were better able to respond to immune reactions than aerial conidia. Further experimentation, however, is required in order to determine whether the observed effects are due to the greater immuneevasion properties of the first two cell types or simply to the fact that they are able to grow faster than the aerial conidia.
The production of different infectious propagules and the wide range of their surface properties imply a diversification of adaptations evolved by fungal pathogens in mediating attachment and adhesion to target insect surfaces. The ability to produce more than one spore type with different surface properties can be expected to increase the possibility of binding diverse ranges of substrata. Biological control applications of entomopathogenic fungi, including $B$. bassiana, often employ aerial conidia as the infective agent; however, the use of other single-cell propagules, such as blastospores and submerged conidia, has also been attempted. Knowledge concerning the forces that mediate interactions between B. bassiana and its host targets can be used to develop formulation conditions for specific targets, with future experiments defining key molecular players in this process likely to yield a wealth of information concerning host-pathogen interactions.

\section{ACKNOWLEDGEMENTS}

The authors wish to thank Dr S. Talham and Sarah Lane (Department of Chemistry, University of Florida,) for their help with AFM, and Dr D. Boucias and Pennipa Prompiboon (Department of Entomology and Nematology, University of Florida) for their assistance with the insect pathology assays.

\section{REFERENCES}

Alves, S. B., Rossi, L. S., Lopes, R. B., Tamai, M. A. \& Pereira, R. M. (2002). Beauveria bassiana yeast phase on agar medium and its pathogenicity against Diatraea saccharalis (Lepidoptera: Crambidae) and Tetranychus urticae (Acari: Tetranychidae). J Invertebr Pathol 81, 70-77.

Bidochka, M. J., Pfeifer, T. A. \& Khachatourians, G. G. (1987). Development of the entomopathogenic fungus Beauveria bassiana in liquid cultures. Mycopathologia 99, 77-83.

Bing, L. A. \& Lewis, L. C. (1991). Suppression of Ostrinia nubilalis (Hubner) (Lepidoptera: Pyralidae) by endophytic Beauveria bassiana (Balsamo) Vuillemin. Environ Entomol 20, 1207-1211.

Bing, L. A. \& Lewis, L. C. (1992). Endophytic Beauveria bassiana (Balsamo) Vuillemin in corn: the influence of the plant growth stage and Ostrinia nubilalis (Hubner). Biocontrol Sci Technol 2, 39-47.

Boucias, D. \& Pendland, J. (1991). Attachment of mycopathogens to cuticle. In The Fungal Spore and Disease Initiation in Plants and Animals. Edited by G. T. Cole \& H. C. Hoch. New York: Plenum Press.

Boucias, D. G., Pendland, J. C. \& Latge, J. P. (1988). Nonspecific factors involved in attachment of entomopathogenic deuteromycetes to host insect cuticle. Appl Environ Microbiol 54, 1795-1805.

Charnley, A. K. \& St Leger, R. (1991). The role of cuticle degrading enzymes in fungal pathogenesis of insects. In The Fungal Spore and Disease Initiation, pp. 267-286. Edited by G. T. Cole \& H. C. Hoch. New York: Plenum Press.

Cho, E. M., Liu, L., Farmerie, W. \& Keyhani, N. O. (2006). EST analysis of cDNA libraries from the entomopathogenic fungus Beauveria (Cordyceps) bassiana. I. Evidence for stage-specific gene expression in aerial conidia, in vitro blastospores and submerged conidia. Microbiology 152, 2843-2854. 
Drozd, C. \& Schwartzbrod, J. (1996). Hydrophobic and electrostatic cell surface properties of Cryptosporidium parvum. Appl Environ Microbiol 62, 1227-1232.

Dufrene, Y. F. (2000). Direct characterization of the physicochemical properties of fungal spores using functionalized AFM probes. Biophys J 78, 3286-3291.

Dunlap, C. A., Biresaw, G. \& Jackson, M. A. (2005). Hydrophobic and electrostatic cell surface properties of blastospores of the entomopathogenic fungus Paecilomyces fumosoroseus. Colloids Surf B Biointerfaces 46, 261-266.

Dynesen, J. \& Nielsen, J. (2003). Surface hydrophobicity of Aspergillus nidulans conidiospores and its role in pellet formation. Biotechnol Prog 19, 1049-1052.

EI-Sayed, G. N., Ignoffo, C. M., Leathers, T. D. \& Gupta, S. C. (1993). Effects of cuticle source and concentration on the expression of hydrolytic enzymes by an entomopathogenic fungus, Nomuraea rileyi. Mycopathologia 122, 149-152.

Fargues, J. (1984). Adhesion of the fungal spore to the insect cuticle in relation to pathogenicity. In Infection Processes of Fungi, pp. 90110. Edited by D. W. Roberts \& J. R. Aist. New York: Rockefeller Foundation.

Fuguet, R., Théraud, M. \& Vey, A. (2004). Production in vitro of toxic macromolecules by strains of Beauveria bassiana, and purification of a chitosanase-like protein secreted by a melanizing isolate. Comp Biochem Physiol C Toxicol Pharmacol 138, 149-161.

Girardin, H., Paris, S., Rault, J., Bellon-Fontaine, M. N. \& Latge, J. P. (1999). The role of the rodlet structure on the physicochemical properties of Aspergillus conidia. Lett Appl Microbiol 29, 364-369.

Greene, G. L., Leppla, N. C. \& Dickerson, W. A. (1976). Velvetbean caterpillar- (Leipidoptera, Noctuidae) rearing procedure and artificial medium. J Econ Entomol 69, 487-488.

Hazen, K. C. (2004). Relationship between expression of cell surface hydrophobicity protein 1 (CSH1p) and surface hydrophobicity properties of Candida dubliniensis. Curr Microbiol 48, 447-451.

Hegedus, D. D., Bidochka, M. J. \& Khachatourians, G. G. (1990). Beauveria bassiana submerged conidia production in a defined medium containing chitin, two hexosamines or glucose. Appl Microbiol Biotechnol 33, 641-647.

Hegedus, D. D., Bidochka, M. J., Miranpuri, G. S. \& Khachatourians, G. G. (1992). A comparison of the virulence, stability and cell-wallsurface characteristics of three spore types produced by the entomopathogenic fungus Beauveria bassiana. Appl Microbiol Biotechnol 36, 785-789.

Holder, D. J. \& Keyhani, N. O. (2005). Adhesion of the entomopathogenic fungus Beauveria (Cordyceps) bassiana to substrata. Appl Environ Microbiol 71, 5260-5266.

Jeffs, L. B., Xavier, I. J., Matai, R. E. \& Khachatourians, G. G. (1999). Relationships between fungal spore morphologies and surface properties for entomopathogenic members of the genera Beauveria, Metarhizium, Paecilomyces, Tolypocladium, and Verticillium. Can J Microbiol 45, 936-948.

Kirkland, B. H., Westwood, G. S. \& Keyhani, N. O. (2004a). Pathogenicity of entomopathogenic fungi Beauveria bassiana and Metarhizium anisopliae to Ixodidae tick species Dermacentor variabilis, Rhipicephalus sanguineus, and Ixodes scapularis. J Med Entomol 41, 705-711.

Kirkland, B. H., Keyhani, N. O. \& Cho, E.-M. (2004b). Differential susceptibility of Amblyomma maculatum and Amblyomma americanum (Acari: Ixodidea) to the entomopathogenic fungi Beauveria bassiana and Metarhizium anisopliae. Biol Control 31, 414-421.

Kirkland, B. H., Eisa, A. \& Keyhani, N. O. (2005). Oxalic acid as a fungal acaracidal virulence factor. J Med Entomol 42, 346-351.
Leathers, T. D., Gupta, S. C. \& Alexander, N. J. (1993). Mycopesticides: status, challenges, and potential. J Ind Microbiol 12, 69-75.

Leckband, D. \& Israelachvili, J. (2001). Intermolecular forces in biology. Q Rev Biophys 34, 105-267.

Ma, H., Snook, L. A., Kaminskyj, S. G. \& Dahms, T. E. (2005). Surface ultrastructure and elasticity in growing tips and mature regions of Aspergillus hyphae describe wall maturation. Microbiology 151, 36793688.

Ma, H., Snook, L. A., Tian, C., Kaminskyj, S. G. \& Dahms, T. E. (2006). Fungal surface remodelling visualized by atomic force microscopy. Mycol Res 110, 879-886.

McCoy, C. W. (1990). Entomogenous fungi as microbial pestidides. In New Directions in Biological Control, pp. 139-159. Edited by R. R. Baker \& P. E. Dunn. New York: A. R. Liss.

Munoz, G. A., Agosin, E., Cotoras, M., Sanmartin, R. \& Volpe, D. (1995). Comparison of aerial and submerged spore properties for Trichoderma harzianum. FEMS Microbiol Lett 125, 63-69.

Paris, S., Debeaupuis, J. P., Crameri, R., Carey, M., Charles, F., Prevost, M. C., Schmitt, C., Philippe, B. \& Latge, J. P. (2003). Conidial hydrophobins of Aspergillus fumigatus. Appl Environ Microbiol 69, 1581-1588.

Pendland, J. C., Hung, S. Y. \& Boucias, D. G. (1993). Evasion of host defense by in vivo-produced protoplast-like cells of the insect mycopathogen Beauveria bassiana. J Bacteriol 175, 5962-5969.

Reithinger, R., Davies, C. R., Cadena, H. \& Alexander, B. (1997). Evaluation of the fungus Beauveria bassiana as a potential biological control agent against phlebotomine sand flies in Colombian coffee plantations. J Invertebr Pathol 70, 131-135.

Samish, M., Ginsberg, H. \& Glazer, I. (2004). Biological control of ticks. Parasitology 129 (Suppl.), S389-S403.

Scholte, E. J., Ng'habi, K., Kihonda, J., Takken, W., Paaijmans, K., Abdulla, S., Killeen, G. F. \& Knols, B. G. (2005). An entomopathogenic fungus for control of adult African malaria mosquitoes. Science 308, 1641-1642.

Singleton, D. R., Fidel, P. L., Wozniak, K. L. \& Hazen, K. C. (2005). Contribution of cell surface hydrophobicity protein I (Cshlp) to virulence of hydrophobic Candida albicans serotype A cells. FEMS Microbiol Lett 244, 373-377.

Smith, S. N., Chohan, R., Armstrong, R. A. \& Whipps, J. M. (1998). Hydrophobicity and surface electrostatic charge of conidia of the mycoparasite Coniothyrium minitans. Mycol Res 102, 243-249.

Strevett, K. A. \& Chen, G. (2003). Microbial surface thermodynamics and applications. Res Microbiol 154, 329-335.

Stringer, M. A. \& Timberlake, W. E. (1995). dewA encodes a fungal hydrophobin component of the Aspergillus spore wall. Mol Microbiol 16, 33-44.

Talaei-Hassanloui, R., Kharazi-Pakdel, A., Goettel, M. \& Mozaffari, J. (2006). Variation in virulence of Beauveria bassiana isolates and its relatedness to some morphological characteristics. Biocontrol Sci Technol 16, 525-534.

Thau, N., Monod, M., Crestani, B., Rolland, C., Tronchin, G., Latgé, J. P. \& Paris, S. (1994). Rodletless mutants of Aspergillus fumigatus. Infect Immun 62, 4380-4388.

Thomas, K. C., Khachatourians, G. G. \& Ingledew, W. M. (1987). Production and properties of Beauveria bassiana conidia cultivated in submerged culture. Can J Microbiol 33, 12-20.

van Oss, C. J., Chaudhury, M. K. \& Good, R. J. (1987). Monopolar surfaces. Adv Colloid Interface Sci 28, 35-64.

Viaud, M., Couteaudier, Y. \& Riba, G. (1998). Molecular analysis of hypervirulent somatic hybrids of the entomopathogenic fungi 
Beauveria bassiana and Beauveria sulfurescens. Appl Environ Microbiol 64, 88-93.

Wilson, W. W., Wade, M. M., Holman, S. C. \& Champlin, F. R. (2001). Status of methods for assessing bacterial cell surface charge properties based on zeta potential measurements. J Microbiol Methods 43, 153-164.
Zhao, L., Schaefer, D. \& Marten, M. R. (2005). Assessment of elasticity and topography of Aspergillus nidulans spores via atomic force microscopy. Appl Environ Microbiol 71, 955-960.

Edited by: S. D. Harris 